\title{
Novel macroporous amphoteric gels: Preparation and characterization
}

\author{
S. Kudaibergenov ${ }^{1,2^{*}}$, Zh. Adilov ${ }^{1}$, D. Berillo ${ }^{2}$, G. Tatykhanova ${ }^{1,2}$, Zh. Sadakbaeva ${ }^{1}$, Kh. Abdullin ${ }^{1}$, \\ I. Galaev ${ }^{3}$ \\ ${ }^{1}$ Laboratory of Engineering Profile, Kazakh National Technical University n/a K.I. Satpaev, Satpaev str. 22, 050013, \\ Almaty, Republic of Kazakhstan \\ ${ }^{2}$ Institute of Polymer Materials and Technology, Panfilov Str. 52/105, 050004, Almaty, Republic of Kazakhstan \\ ${ }^{3}$ DSM Food Specialties B.V., PO Box 1, 2600 MA Delft, The Netherlands
}

Received 4 July 2011; accepted in revised form 26 November 2011

\begin{abstract}
Macroporous amphoteric gels based on allylamine, methacrylic acid and acrylamide crosslinked by N,N'-methylenebisacrylamide were synthesized by radical copolymerization of monomers in cryoconditions. The composition of cryogels was determined by combination of potentiometric and conductimetric titrations. The morphology of cryogels was evaluated by scanning electron microscope (SEM). Cryogels exhibited sponge-like porous structure with pore size ranging from 50 to $200 \mu \mathrm{m}$. The values of the isoelectric points (IEPs) determined from the swelling experiments arranged between 3.5 and 4.3. The high adsorption-desorption capacity of amphoteric cryogels with respect to $\mathrm{mM}$ and trace concentrations of copper, nickel, and cobalt ions was demonstrated. It was shown that the macroporous amphoteric cryogels are able to adsorb up to $99.9 \%$ of copper, nickel, and cobalt ions from $10^{-3} \mathrm{~mol} \cdot \mathrm{L}^{-1}$ aqueous solution.
\end{abstract}

Keywords: polymer gels, smart polymers, macroporous amphoteric cryogels, morphology, swelling

\section{Introduction}

Hydrogels can be in the form of macroscopic networks or confined to smaller dimensions such as microgels, which are crosslinked polymeric particles [1]. When the size of microgels is in the submicron range, they are known as nanogels [2]. According to the IUPAC definition, materials having pores of larger than $50 \mathrm{~nm}$ are called macroporous [3]. However, recently much attention is paid to the materials with pore sizes between 1-100 microns, and beyond. Such polymers sometimes are called supermacroporous polymers. According to the cryopolymerization concept macroporous gels are formed in moderately frozen solutions of monomeric and/or polymeric precursors. Contrary to conventional gels in which solvent is retained within the volume, the cryogels are heterophase systems where solvent resides both inside the interconnected macropores and is bound to the polymer network. Comprehensive information on the structure, properties and application of cryogels based on natural and synthetic polymers can be found in a review article [4]. Recently published fundamental book [5] describes both the pioneering articles devoted to cryogels and gives an up-to-date compilation of modes of production of macroporous hydrogels, characterization of such materials, and applications with regard to both biotechnology and biomedicine.

Synthetic amphoteric gels belong to 'smart' materials due to their response to temperature, $\mathrm{pH}$, ionic strength, water-organic solvent composition, electric field, etc. $[6,7]$. In the last years the most attention was paid to amphoteric nanogels [8-15] and microgels [16-20] however, to our knowledge, there

\footnotetext{
${ }^{*}$ Corresponding author, e-mail: ipmt-kau@usa.net
}

(c) BME-PT 
is no any available information on macroporous amphoteric gels of synthetic origin. Amphoteric cryogels as distinct from nonionic, anionic and cationic macroporous materials consist of both acidic and basic monomers.

In the present communication we report for the first time the preparation protocol and characterization of amphoteric cryogels that will have potential applications for the encapsulation of cells, immobilization of enzymes, purification and separation of proteins, recovery of metal ions and as catalysts.

\section{Experimental part}

\subsection{Materials}

Monomers and initiators - acrylamide (AAm, 99\% purity, from Sigma-Aldrich Chemical Co., Milwaukee, WI, USA), allylamine (AA, 99\% purity, from Sigma-Aldrich Chemical Co., Milwaukee, WI, USA), methacrylic acid (MAA, 99\% purity, from Sigma-Aldrich Chemical Co., Milwaukee, WI, USA), N,N,N',N'-tetramethylethylenediamine (TMED, 99\% purity, from Sigma-Aldrich Chemical Co., Milwaukee, WI, USA), ammonium persulfate (APS, 99\% purity), and crosslinking agent N,N'-methylenbisacrylamide (MBAA, 99\% purity, from SigmaAldrich Chemical Co., Milwaukee, WI, USA) were purchased from Aldrich and used without further purification.

\subsection{Synthesis of amphoteric cryogels}

A mixture of AA (66 mg or $1.15 \mathrm{mmol}), \mathrm{MAA}(99 \mathrm{mg}$ or $1.15 \mathrm{mmol}$ ), AAm (660 mg or $9.3 \mathrm{mmol}$ ), MBAA $(82 \mathrm{mg}$ ) corresponding to molar ratio of monomers AA:MAA:AAm $=10: 10: 80 \mathrm{~mol} \% / \mathrm{mol} \% / \mathrm{mol} \%$ was dissolved in $9.7 \mathrm{~mL}$ of deionized water, flushed by nitrogen for $10 \mathrm{~min}$ and degassed in vacuo for about $5 \mathrm{~min}$ to eliminate the dissolved oxygen. After addition of $10 \mu \mathrm{L}$ of TMED the solution was cooled in an ice bath for $4-5 \mathrm{~min}$. Then $0.1 \mathrm{~mL}$ of aqueous solution of APS (10 wt \%) preliminary cooled in an ice bath for 4-5 min was added and the reaction mixture was stirred for $1 \mathrm{~min}$. The total volume of reaction mixture was divided into 10 parts and each part containing $1 \mathrm{~mL}$ of reaction mixture was placed into the 10 plastic syringes with diameter $5 \mathrm{~mm}$ with closed outlet at the bottom. The solution in syringe was frozen within $10 \mathrm{~min}$ at $-12^{\circ} \mathrm{C}$ and was kept frozen during $48 \mathrm{~h}$. After completion of the reaction the sample was thawed at room temperature. The prepared cryogel sample was washed out thoroughly by distilled water every $2-3$ hours during several days then successively washed out by 25 , 50,75 and $96 \%$ ethanol to dehydrate then dried in air and finally in vacuum oven to constant mass at room temperature. The amount of monomers in initial feed (in $\mathrm{mg}$ and $\mathrm{mol} \%$ ) used for synthesis of cryogels with different molar ratio of monomers at constant concentration of MBAA ( $82 \mathrm{mg}$ or $10 \mathrm{wt} \%$ ) is given in Table 1 .

Thus a series of amphoteric cryogels (ACG) with initial molar ratios of AA:MAA:AAm = 10:10:80;

Table 1. Amount of AA, MAA and AAm in the feed used for synthesis of cryogels

\begin{tabular}{|c|c|c|c|c|c|}
\hline \multicolumn{5}{|c|}{ Initial monomer feed } \\
\hline AA & MAA & AAm & AA & MAA & AAm \\
\hline 131.3 & 197.8 & 460.6 & 20 & 20 & 60 \\
\hline 197.0 & 296.7 & 327.0 & 30 & 30 & 40 \\
\hline 262.7 & 395.6 & 163.5 & 40 & 40 & 20 \\
\hline 328.3 & 494.5 & 0 & 50 & 50 & 0 \\
\hline
\end{tabular}

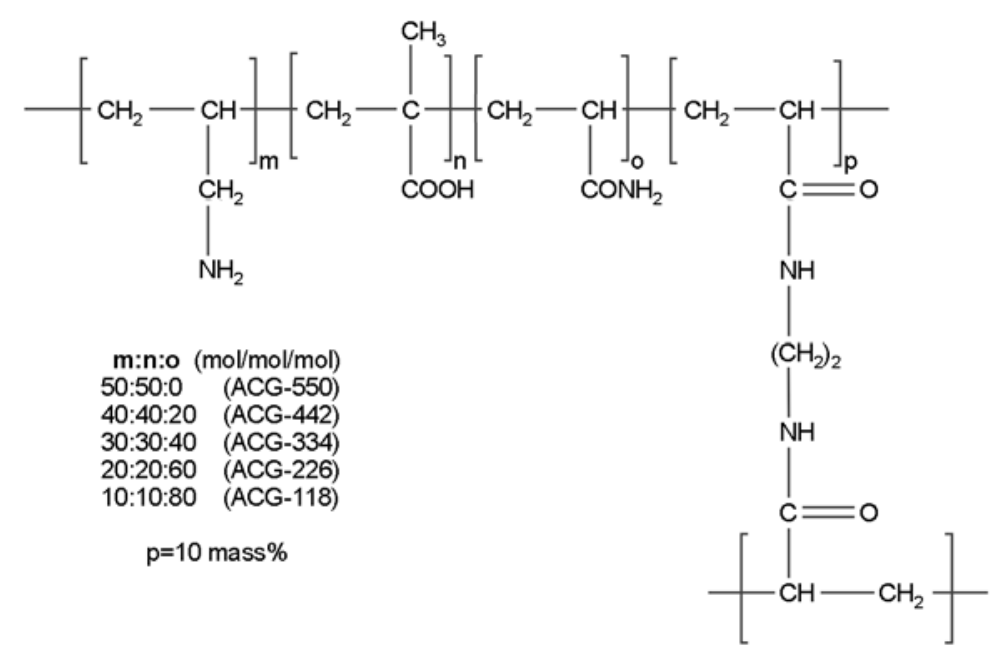

Figure 1. Structural units of amphoteric cryogels derived from AA, MAA and AAm crosslinked by MBAA 
$20: 20: 60, \quad 30: 30: 40, \quad 40: 40: 20 \quad$ and 50:50:0 $\mathrm{mol} \% / \mathrm{mol} \% / \mathrm{mol} \%$ were synthesized and abbreviated as ACG-118, ACG-226, ACG-334, ACG-442 and ACG-550 (Figure 1).

\subsection{Potentiometric and conductimetric titrations}

The fine powdered cryogel samples $(10 \mathrm{mg})$ were put to $10 \mathrm{~mL}$ of distilled water, stirred $1 \mathrm{~h}$ and titrated by $0.1 \mathrm{M} \mathrm{HCl}$ or $\mathrm{KOH}$. Potentiometric and conductimetric titrations were carried out on the $\mathrm{pH} /$ conductivity meter 'Mettler Toledo MFC 227' (Switzerland) at room temperature. For calculation of $\mathrm{pK}_{\mathrm{b}}$ of allylamine groups the Henderson-Hasselbalch equation $\mathrm{pOH}=\mathrm{pK}_{\mathrm{b}}+n \cdot \log (\beta /(1-\beta)$ ) (where $\beta$ is the degree of ionization of primary amine groups of cryogels, $n$ is the specific parameter for polyelectrolytes) was used.

\subsection{Swelling experiments}

The swelling capacity of cryogel samples as a function of $\mathrm{pH}$ was evaluated from the height measurements. For this dry gel sample with diameter $5 \mathrm{~mm}$ and height $10 \mathrm{~mm}$ was placed into a glass tube with diameter $10 \mathrm{~mm}$ the bottom of which was closed by Shott filter ended by valve. After passing of $100 \mathrm{~mL}$ of aqueous solutions through a gel sample with desired $\mathrm{pH}$, that was adjusted by addition of $0.1 \mathrm{~N}$ $\mathrm{HCl}$ or $\mathrm{KOH}$ to distilled water to avoid the influence of buffer on swelling behavior, its height was accurately measured $[16,17]$. Swelling experiments were repeated three times with experimental error not exceeding $\pm 5 \%$. The ratio of $L_{\mathrm{s}} / L_{0}$ (where $L_{\mathrm{s}}$ is the height of swollen gel, $L_{0}$ is the height of dry gel) on $\mathrm{pH}$ was plotted. The flow-rate of water passing through the cryogel samples was measured at a constant hydrostatic pressure equal to $100 \mathrm{~cm}$ of water column corresponding to a pressure of ca. $0.01 \mathrm{MPa}$ as described in [21]. Measurements were repeated three times and the values averaged.

\subsection{Sorption of metal ions}

Sorption of $\mathrm{Cu}^{2+}, \mathrm{Ni}^{2+}$, and $\mathrm{Co}^{2+}$ ions by ACG-334 was performed as follows: a piece of dry sample with diameter $5 \mathrm{~mm}$ and height $10 \mathrm{~mm}$ was placed inside of the glass tube with diameter $5 \mathrm{~mm}$ and height $50 \mathrm{~mm}$ the bottom of which was closed by Shott filter ended by valve. Then $1000 \mathrm{~mL}$ of aqueous solution of metal salts or their mixture with concentrations $10^{-3}$ or $10^{-5} \mathrm{~mol} / \mathrm{L}$ was passed through the sample during 1 day. Desorption of metal ions was carried out by passing through gel sample $25 \mathrm{~mL}$ of $0.1 \mathrm{~N} \mathrm{HCl}$ several times.

\subsection{Methods}

For SEM measurements cryogel samples were preliminary dehydrated by ethanol and dried at room temperature then in vacuum oven. The cylindrical sample with diameter $5 \mathrm{~mm}$ and height $10 \mathrm{~mm}$ was carefully cut by knife blade in parallel or perpendicular to the long axes and the longitudinal and cross sectional parts coated and uncoated with aluminum were examined on scanning electron microscope JSM5800 (Jeol, Japan). Probably due to the presence of electrically conducting amine and carboxylic groups we were able to observe the fine structure and longitudinal and cross sectional morphology of uncoated with aluminum cryogels samples. The concentration of adsorbed and desorbed metal ions was determined with the help of ion-plasma coupled emission spectrometer Optima 5100 DV (Perkin Elmer, USA). FTIR spectra were recorded on an Alpha-P (Bruker, Germany) in $\mathrm{KBr}$ pellets.

\section{Results and discussion}

Figure 2 shows the potentiometric and conductimetric titration curves of amphoteric cryogels. Gradual shifting of the inflection points to left side confirms overall decreasing of the content of carboxylic and amine groups in cryogels in the following order: ACG-550>ACG-442>ACG-334>ACG$226>$ ACG-118 and it is in good agreement with the variation of acid and base monomers in the feed. Compositions of amphoteric cryogels found from potentiometric and conductimetric titration curves together with ionization constant of allylamine groups $\left(\mathrm{pK}_{\mathrm{b}}\right)$ and isoelectric $\mathrm{pH}\left(\mathrm{pH}_{\mathrm{IEP}}\right)$ are shown in Table 2.

For different samples the average molar composition of amphoteric cryogels found from the potentiometric titration curves is equal to $55.5 \pm 2.0 \mathrm{~mol} \%$ of $\mathrm{COOH}$ group and to $44.5 \pm 2.0 \mathrm{~mol} \%$ of $\mathrm{NH}_{2}$ group while acid-base content found from conductometric titration curves corresponds to $63 \pm 4 \mathrm{~mol} \%$ of $\mathrm{COOH}$ group and $37 \pm 4 \mathrm{~mol} \% \mathrm{NH}_{2}$ group. In spite of inconsistency of potentiometric and conductimetric titration data, they indicate that the composition of amphoteric cryogels is lightly enriched by 

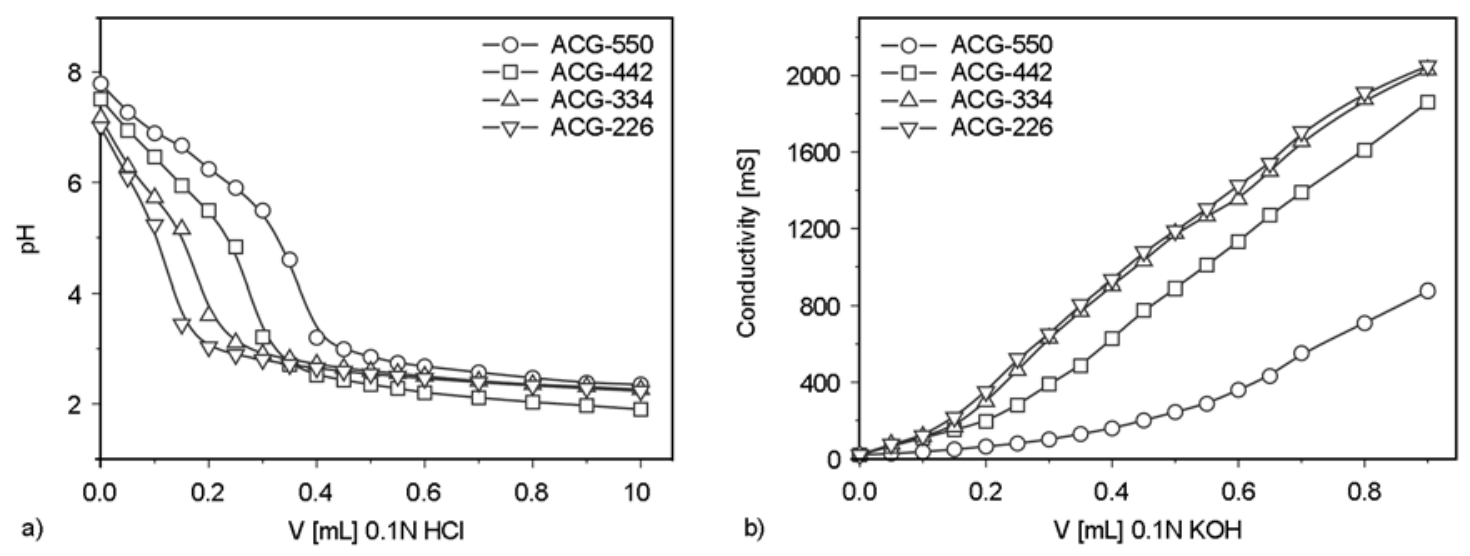

Figure 2. Potentiometric (a) and conductimetric (b) titration curves of amphoteric cryogels by $0.1 \mathrm{M} \mathrm{HCl}(\mathrm{a})$ and $\mathrm{KOH}$ (b)

Table 2. Composition, ionization constant of allylamine groups $\left(\mathrm{pK}_{\mathrm{b}}\right)$ and the isoelectric $\mathrm{pH}\left(\mathrm{pH}_{\mathrm{IEP}}\right)$ of cryogels

\begin{tabular}{|c|c|c|c|c|c|c|}
\hline \multirow[b]{2}{*}{ Cryogels } & \multicolumn{2}{|c|}{$-\mathrm{NH}_{2}$ groups [mol\%] } & \multicolumn{2}{|c|}{-COOH groups [mol\%] } & \multirow[b]{2}{*}{$\mathbf{p} \mathbf{K}_{\mathrm{b}}$} & \multirow[b]{2}{*}{$\mathrm{pH}_{\text {IEP }}$} \\
\hline & $\begin{array}{c}\text { Potentiometric } \\
\text { titration }\end{array}$ & $\begin{array}{c}\text { Conductimetric } \\
\text { titration }\end{array}$ & $\begin{array}{l}\text { Potentiometric } \\
\text { titration }\end{array}$ & $\begin{array}{c}\text { Conductimetric } \\
\text { titration }\end{array}$ & & \\
\hline ACG-550 & 46.7 & 41.0 & 53.3 & 59.0 & 5.44 & 4.0 \\
\hline ACG-442 & 42.4 & 37.0 & 57.6 & 63.0 & 5.25 & 4.1 \\
\hline ACG-334 & 43.3 & 33.3 & 56.7 & 66.6 & 5.78 & 4.2 \\
\hline ACG-226 & - & 41.4 & - & 58.6 & 5.62 & 4.3 \\
\hline ACG-118 & $\begin{array}{cc}- \\
-\end{array}$ & 38.5 & - & 61.5 & - & 3.5 \\
\hline
\end{tabular}

acidic monomer probably due to relatively low activity of AA monomer in the copolymerization reaction [22].

The values of $\mathrm{pK}_{\mathrm{b}}$ for ACG-550, ACG-442 ACG334 and ACG-226 determined from Henderson-
Hasselbalch equation are equal to $5.44 ; 5.25 ; 5.78$ and 5.62 respectively. Such values of $\mathrm{pK}_{\mathrm{b}}$ suggest effective complexation of allylamine groups with transition metal ions and formation of coordination bonds.

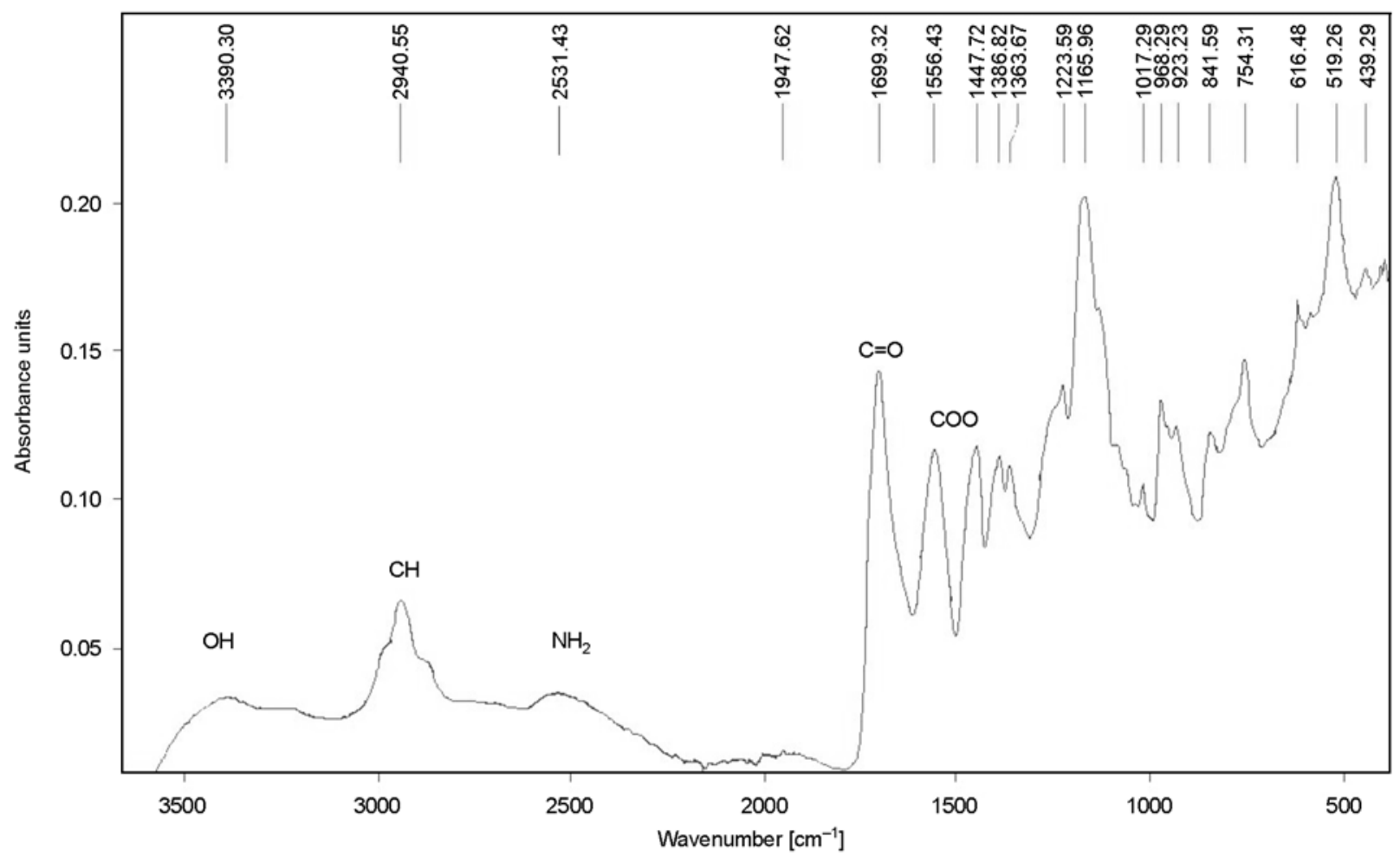

Figure 3. FTIR spectra of dry ACG-334 
FTIR spectra of amphoteric cryogels show the characteristic bands of $\mathrm{COO}^{-}\left(1556 \mathrm{~cm}^{-1}\right), \mathrm{C}=\mathrm{O}$ $\left(1699 \mathrm{~cm}^{-1}\right), \mathrm{NH}_{3}{ }^{+}\left(2532 \mathrm{~cm}^{-1}\right), \mathrm{CH}\left(2940 \mathrm{~cm}^{-1}\right)$, and $\mathrm{OH}\left(3390 \mathrm{~cm}^{-1}\right)$ groups (Figure 3). The appearance of the band at $3390 \mathrm{~cm}^{-1}$ can be attributed to $\mathrm{OH}$ groups of hydrated water tightly bonded to functional groups of cryogels. Coexistence of $\mathrm{COO}^{-}$ and $\mathrm{NH}_{3}{ }^{+}$reveals the zwitterionic structure of cryogels due to the fact that partly transition of protons from carboxylic groups to amine one may take place.

According to a commonly adopted concept $[4,5]$ cryogels can contain closed-, open-, or through pores that permit liquid to fill them and ensure unhindered convectional flow of solutes within interconnected pores. Cross- and longitudinal sections of dry ACG118 and ACG-442 show sponge-like porous structure with pore size ranging from 50 to $200 \mu \mathrm{m}$ (Figure $4 \mathrm{a}-4 \mathrm{~d}$ ) and the interconnected channels (Figure $4 b)$.

Dynamics of water flux through the cryogel samples with a diameter $5 \mathrm{~mm}$ and height $10 \mathrm{~mm}$ were evaluated (Table 2). Increasing of the content of

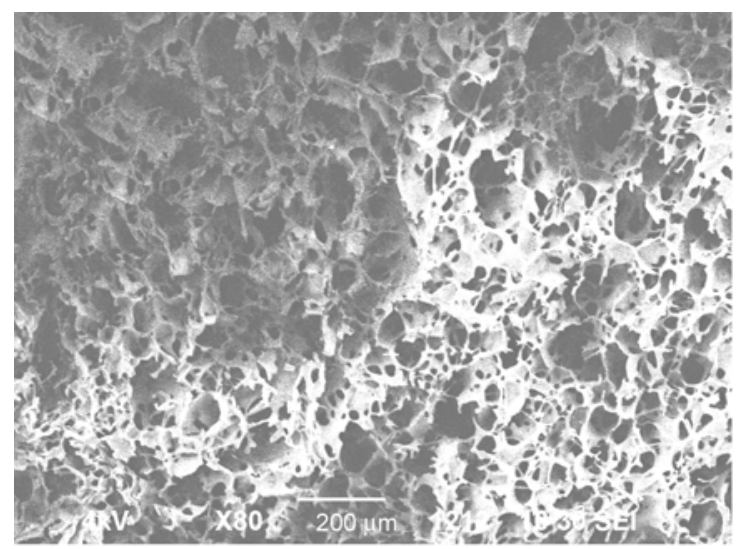

a)

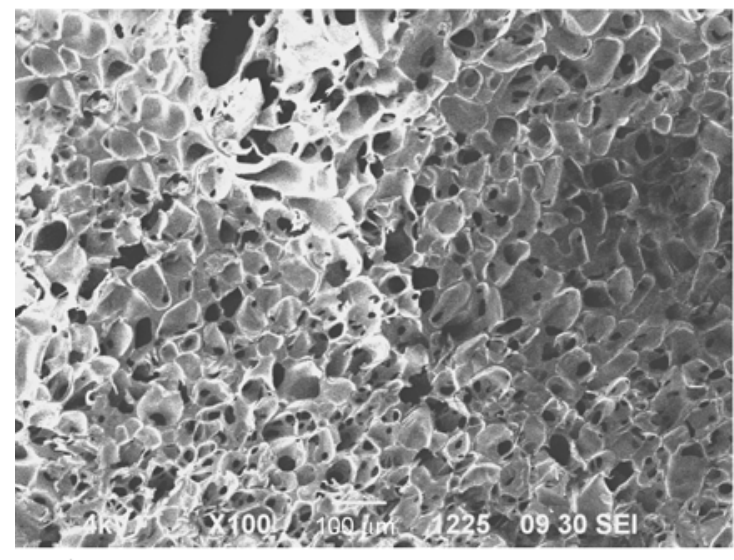

c) acidic and basic monomers in a series of ACGs leads to progressive decreasing of water flux. This phenomenon can probably be explained by different hydration degrees of ionic groups leading to 'apparent' decreasing of pore size of cryogels (Table 3).

One of the specific features of linear and crosslinked polyampholytes is the existence of so-called isoelectric points (IEPs) where intra- and intermolecular attractions of opposite fixed charges lead to pseudoneutral behavior and compact structure of amphoteric macromolecules [6, 7]. Figure 5 shows the swelling and deswelling of amphoteric cryogels as a function of $\mathrm{pH}$. It is seen that the deswelling of amphoteric cryogels is minimal at the IEPs. The iso-

Table 3. Dynamics of water flow-rate through amphoteric cryogels

\begin{tabular}{|c|c|}
\hline Amphoteric cryogels & Water flux [mL/min] \\
\hline ACG-118 & $1.20 \pm 0.10$ \\
\hline ACG-226 & $0.35 \pm 0.05$ \\
\hline ACG-334 & $0.18 \pm 0.05$ \\
\hline ACG-442 & $0.05 \pm 0.01$ \\
\hline ACG-550 & $0.02 \pm 0.01$ \\
\hline
\end{tabular}

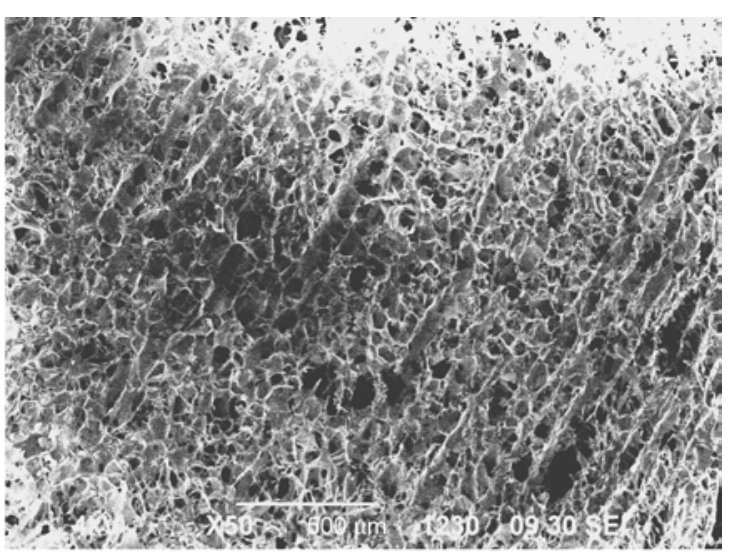

b)

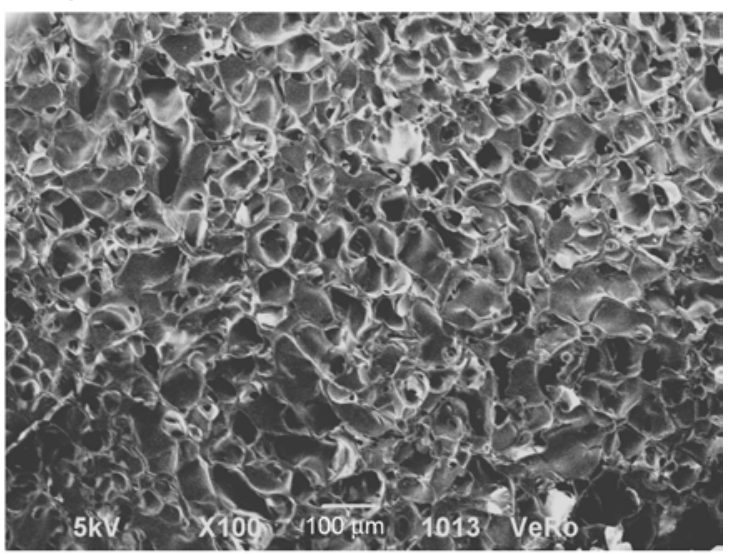

d)

Figure 4. SEM images of cross (a, c, d) and longitudinal (b) sections of ACG-118 (a, b) and ACG-442 (c, d) uncoated (a, b, c) and coated (d) with aluminum 


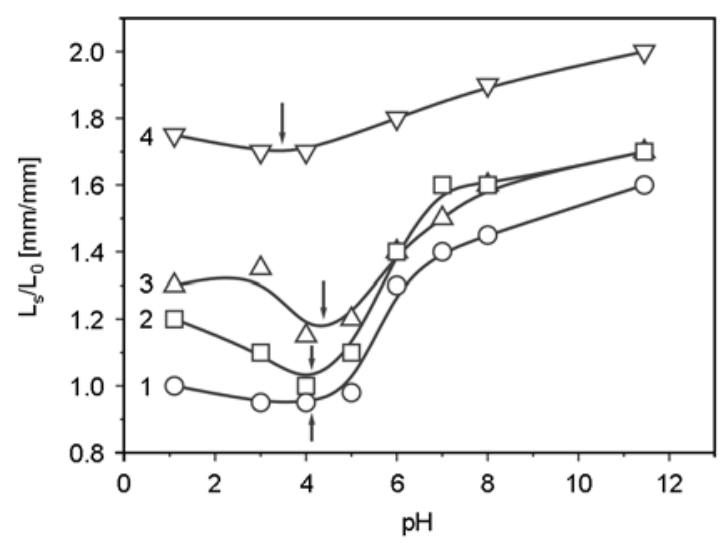

Figure 5. Swelling-deswelling curves of cryogels ACG-550 (curve 1), ACG-334 (curve 2), ACG-226 (curve 3), and ACG-118 (curve 4) on $\mathrm{pH}$. Arrows show the IEPs

electric $\mathrm{pH}\left(\mathrm{pH}_{\mathrm{IEP}}\right)$ of amphoteric cryogels found from the swelling-deswelling measurements arranges between 3.5 and 4.3 (see Table 2).

The ability of cryogels to bind metal ions was also studied. Sorption of metal ions is accompanied by colourization of samples. This may be due both existing of free (uncomplexed) metal ions and metal ions coordinated with amine and/or carboxylic groups within cryogels (Figure 6). Involvement of allylamine groups into complexation reaction with transition metals ions and formation of chelate structure was studied earlier [23].

As seen from Table 4 the ACG-334 adsorbs up to $99.9 \%$ of metal ions from aqueous solution containing $10^{-3} \mathrm{~mol} / \mathrm{L}$ of copper, nickel, and cobalt ions. In the course of passing of $1000 \mathrm{~mL}$ of metal ions with concentration of $10^{-5}$ and $10^{-3} \mathrm{~mol} / \mathrm{L}$ through amphoteric cryogel ACG-334 gradually colorization of cryogel samples (especially for copper ions) was observed that is in favour of complexation reaction. The sorption capacity of ACG-334 with respect to

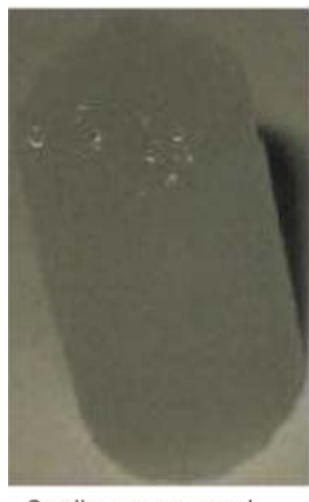

Swollen pure cryogel

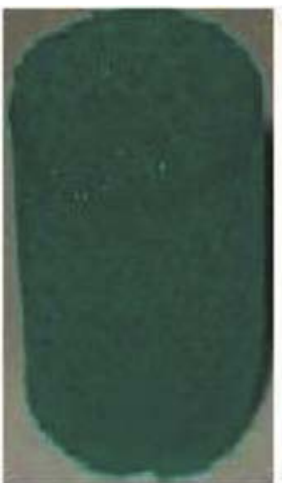

$\mathrm{Cu}$
Table 4. Adsorbed and desorbed amounts of metal ions by ACG-334

\begin{tabular}{|c|c|c|c|}
\hline \multirow{2}{*}{$\begin{array}{c}\text { Type of } \\
\text { metal ions }\end{array}$} & $\begin{array}{c}\text { Concentration } \\
\begin{array}{c}\text { Co metal ions passed } \\
\text { through ACG-334 [ mol/L] }\end{array}\end{array}$ & $\begin{array}{c}\text { Adsorbed } \\
{[\%]}\end{array}$ & $\begin{array}{c}\text { Desorbed } \\
{[\%]}\end{array}$ \\
\hline $\mathrm{Cu}^{2+}$ & \multirow{2}{*}{$10^{-3}$} & 99.9 & 51.4 \\
\hline $\mathrm{Ni}^{2+}$ & & 99.9 & 67.2 \\
\hline $\mathrm{Co}^{2+}$ & \multirow{2}{*}{$10^{-5}$} & 99,9 & 62.0 \\
\hline $\mathrm{Cu}^{2+}$ & & 65.0 & 98.8 \\
\hline $\mathrm{Ni}^{2+}$ & & 73.0 & 95.2 \\
\cline { 1 - 1 } $\mathrm{Co}^{2+}$ & & 72.3 & 91.1 \\
\hline
\end{tabular}

$10^{-3} \mathrm{~mol} / \mathrm{L}$ of copper, nickel, and cobalt ions is equal to $634.9 ; 586.4 ; 588.7 \mathrm{mg}$ respectively per $1 \mathrm{~g}$ of dry cryogel while the same parameter for $10^{-5} \mathrm{~mol} / \mathrm{L}$ of copper, nickel, and cobalt ions is correspondingly equal to $41.3 ; 42.8$ and $42.7 \mathrm{mg}$ per $1 \mathrm{~g}$ of dry sample.

Desorption of metal ions by $0.1 \mathrm{~N} \mathrm{HCl}$ is in the range from 51 to $67 \%$. In spite of the fact that the adsorbed amount of metal ions from aqueous solution containing $10^{-5} \mathrm{~mol} / \mathrm{L}$ is low, the desorbed amount of copper, nickel, and cobalt ions is high and equal to 98.8; 95.2 and $91.1 \%$ respectively. Preferentially adsorption of $\mathrm{Cu}^{2+}$ ions (79\%) in comparison with $\mathrm{Ni}^{2+}(38 \%)$ and $\mathrm{Co}^{2+}$ ions (32\%) from their mixture was also observed from aqueous solution containing $10^{-5} \mathrm{~mol} / \mathrm{L}$ of metal ions indicating on the specific binding of copper ions. High adsorption capacity of amphoteric macroporous gels with respect to $\mathrm{mM}$ and trace metal ions may be perspective for purification of the wastewaters and analytical purposes. The reduction of cryogel-metal complexes by $\mathrm{NaBH}_{4}$ leads to formation of nano- and micronsized particles of metals in reduced and oxidized forms $[24,25]$ immobilized on the inner and surface parts of amphoteric cryogels. The chemical composition of the Ni containing sample by energy dispersive X-ray

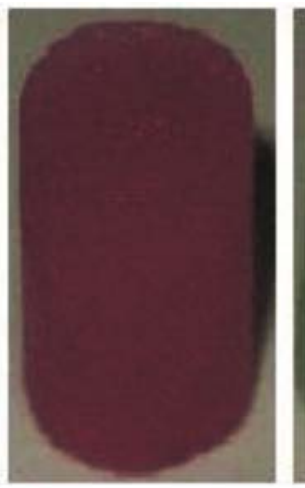

Co

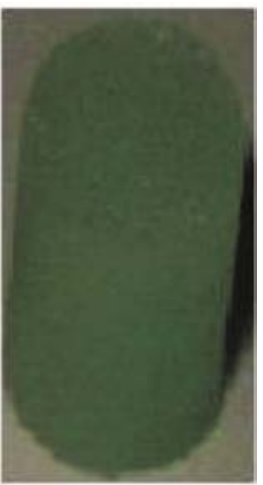

$\mathrm{Ni}$

Figure 6. Adsorption of metal ions by macroporous amphoteric cryogel ACG-334 
attached to SEM revealed that up to $34 \%$ mass \% of $\mathrm{Ni}$ particles are formed. Thus amphoteric cryogels can serve as efficient heterogeneous supports for metal nanoparticles and as flow microreactors in catalysis.

\section{Conclusions}

SEM images of cross- and longitudinal sections of amphoteric cryogels show sponge-like porous structure and the interconnected channels. The content of acid-base groups determined by combination of potentiometric and conductimetric titrations is in favour of acidic groups. The isoelectric points of amphoteric cryogels found from the swelling measurements are arranged between 3.5 and 4.3. It has been shown that macroporous amphoteric cryogels are able to adsorb up to $99.9 \%$ of copper, nickel, and cobalt ions from $10^{-3} \mathrm{~mol} / \mathrm{L}$ aqueous solution while to desorb from 91 to $98 \%$ metal ions from $10^{-5} \mathrm{~mol} / \mathrm{L}$ aqueous solution. Desorption of metal ions by $0.1 \mathrm{~N} \mathrm{HCl}$ ranges from 51 to $69 \%$. Specific sorption of copper ions by amphoteric cryogel from the mixture of copper, nickel, and cobalt ions with concentration of $10^{-5} \mathrm{~mol} / \mathrm{L}$ is also observed.

\section{Acknowledgements}

Financial support from the Ministry of Education and Science of the Republic of Kazakhstan is greatly acknowledged

\section{References}

[1] Oh J. K., Drumright R., Siegwart D. J., Matyjaszewski K.: The development of microgels/nanogels for drug delivery applications. Progress in Polymer Science, 33, 448-477 (2008).

DOI: $10.1016 /$ j.progpolymsci.2008.01.002

[2] Graham N. B., Cameron A.: Nanogels and microgels: The new polymeric materials playground. Pure and Applied Chemistry, 70, 1271-1275 (1998).

DOI: $10.1351 /$ pac199870061271

[3] Sing K. S. W., Everett D. H., Haul R. A. W., Moscou L., Pierotti R. A., Rouquérol J., Siemieniewska T.: Reporting physisorption data for gas/solid systems with special reference to the determination of surface area and porosity. Pure and Applied Chemistry, 57, 603-619 (1985). DOI: $10.1351 / \mathrm{pac} 198557040603$

[4] Lozinskiy V. I.: Cryogels on the basis of natural and synthetic polymers: Preparation, properties and application. Russian Chemical Reviews, 71, 489-511 (2002). DOI: $10.1070 / \mathrm{RC} 2002 \mathrm{v} 071 \mathrm{n} 06 \mathrm{ABEH} 000720$
[5] Mattiasson B., Kumar A., Galaev I.: Macroporous polymers: Production, properties and biotechnological/biomedical applications. CRC Press, Boca Raton (2010).

[6] Kudaibergenov S. E.: Polyampholytes. Synthesis, characterization and application. Kluwer Academic/Plenum Publishers, New York (2002).

[7] Kudaibergenov S. E.: Polyampholytes. Encyclopedia of polymer science and technology. Wiley, New York (2008).

DOI: $10.1002 / 0471440264 . p s t 562$

[8] Ogawa K., Nakayama A., Kokufuta E.: Preparation and characterization of thermosensitive polyampholyte nanogels. Langmuir, 19, 3178-3184 (2003).

DOI: $10.1021 / \mathrm{la} 0267185$

[9] Ogawa K., Nakayama A., Kokufuta E.: Electrophoretic behavior of ampholytic polymers and nanogels. The Journal of Physical Chemistry B, 107, 82238227 (2003).

DOI: $10.1021 / \mathrm{jp} 022366 \mathrm{z}$

[10] Deng L., Zhai Y., Guo S., Jin F., Xie Z., He X., Dong A.: Investigation on properties of $\mathrm{P}((\mathrm{MAA}-\mathrm{Co}-\mathrm{DMAEMA})-$ g-EG) polyampholyte nanogels. Journal of Nanoparticle Research, 11, 365-374 (2009). DOI: $10.1007 / \mathrm{s} 11051-008-9391-2$

[11] Hu J., Yu S., Yao P.: Stable amphoteric nanogels made of ovalbumin and ovotransferrin via self-assembly. Langmuir, 23, 6358-6364 (2007). DOI: $10.1021 / 1 \mathrm{a} 063419 \mathrm{x}$

[12] Yu S., Hu J., Pan P., Yao P., Jiang M.: Stable and pHsensitive nanogels prepared by self-assembly of chitosan and ovalbumin. Langmuir, 22, 2754-2759 (2006). DOI: $10.1021 / \mathrm{la} 053158 \mathrm{~b}$

[13] Miyake M., Ogawa K., Kokufuta E.: Light-scattering study of polyelectrolyte complex formation between anionic and cationic nanogels in an aqueous salt-free system. Langmuir, 22, 7335-7341 (2006).

DOI: $10.1021 / 1 \mathrm{a060701 \textrm {v }}$

[14] Doi R., Kokufuta E.: On the water dispersibility of a 1:1 stoichiometric complex between a cationic nanogel and linear polyanion. Langmuir, 26, 13579-13589 (2010).

DOI: $10.1021 / 1 \mathrm{a} 101852 \mathrm{~b}$

[15] Wu W., Mitra N., Yan E. C. Y., Zhou S.: Multifunctional hybrid nanogel for integration of optical glucose sensing and self-regulated insulin release at physiological pH. ACS Nano, 4, 4831-4839 (2010).

DOI: $10.1021 / \mathrm{nn} 1008319$

[16] Tan B. H., Ravi P., Tam K. C.: Synthesis and characterization of novel $\mathrm{pH}$-responsive polyampholyte microgels. Macromolecular Rapid Communications, 27, 522528 (2006). DOI: $10.1002 / \mathrm{marc} .200500830$

[17] Christodoulakis K. E., Vamvakaki M.: Amphoteric core-shell microgels: Contraphilic two-compartment colloidal particles. Langmuir, 26, 639-647 (2010). DOI: 10.1021/la902231b 
[18] Schachschal S., Balaceanu A., Melian C., Demco D. E., Eckert T., Richtering W., Pich A.: Polyampholyte microgels with anionic core and cationic shell. Macromolecules, 43, 4331-4339 (2010).

DOI: $10.1021 / \mathrm{ma100184h}$

[19] Ni H., Kawaguchi H., Endo T.: Preparation of amphoteric microgels of poly(acrylamide/methacrylic acid/ dimethylamino ethylene methacrylate) with a novel pH-volume transition. Macromolecules, 40, 63706376 (2007).

DOI: $10.1021 / \mathrm{ma} 070358 \mathrm{~g}$

[20] Hoare T., Pelton R.: Charge-switching, amphoteric glucose-responsive microgels with physiological swelling activity. Biomacromolecules, 9, 733-740 (2008).

DOI: $10.1021 / \mathrm{bm} 701203 \mathrm{r}$

[21] Arvidsson P., Plieva F. M., Savina I. N., Fexby S., Bülow L., Galaev I. Y., Mattiasson B.: Chromatography of microbial cells using continuous supermacroporous affinity and ion-exchange columns. Journal of Chromatography A, 977, 27-38 (2002).

DOI: $10.1016 / \mathrm{S} 0021-9673(02) 01114-7$
[22] Kabanov V. A., Topchiev D. A.: Polymerization of ionizing monomers. Nauka, Moscow (1975).

[23] Bekturov E. A., Kudaibergenov S. E., Zhaimina G. M., Saltykov Y. P., Pel'Menstein B. Y.: Complexation of polyallylamine with transition metal ions in aqueous solution. Die Makromolekulare Chemie, Rapid Communications, 7, 339-343 (1986).

DOI: $10.1002 /$ marc.1986.030070603

[24] Park B. K., Jeong S., Kim D., Moon J., Lim S., Kim J. S.: Synthesis and size control of monodisperse copper nanoparticles by polyol method. Journal of Colloid and Interface Science, 311, 417-424 (2007). DOI: $10.1016 /$ j.jcis.2007.03.039

[25] Liu X., Guo M., Zhang M., Wang X., Guo X., Chou $\mathrm{K}$.: Effects of PVP on the preparation and growth mechanism of monodispersed Ni nanoparticles. Rare Metals, 27, 642-647 (2008). DOI: $10.1016 / \mathrm{S} 1001-0521(08) 60198-9$ 